Asian-Australasian Journal of

Food Safety and Security

ISSN 2523-1073 (Print) 2523-2983(Online)

www.ebupress.com/journal/aajfss

\title{
Article
}

\section{Socio economic impact, coastal land use pattern and livelihood status of Shyamnagar upazila, Satkhira, Bangladesh}

\author{
Abdullah Al Mamun Siddiqui ${ }^{1,4^{*}}$, Md. Abul Kashem ${ }^{2}$, Md. Atiqul Islam Mondal ${ }^{1}$, Md. Masum Billah $^{3}$, Shariful \\ Islam $^{1}$ and Mohammad Nazmul Hasan ${ }^{1}$ \\ ${ }^{1}$ Institute of Marine Sciences and Fisheries, University of Chittagong, Chittagong - 4331, Bangladesh \\ ${ }^{2}$ Department of Oceanography, Dhaka University, Bangladesh \\ ${ }^{3}$ Department of Land Management, Faculty of Agriculture, University Putra Malaysia, 43400 UPM, Serdang, \\ Selangor Darul Ehsan, Malaysia \\ ${ }^{4}$ Pragmatic Foundation, Tangail, Bangladesh
}

*Corresponding author: Abdullah Al Mamun Siddiqui, Pragmatic Foundation, West Lane of Singer Show Room, Victoria Road, Tangail-1900, Bangladesh. E-mail: siddiquiimsfcu@gmail.com

Received: 24 August 2020/Accepted: 12 October 2020/ Published: 30 November 2020

\begin{abstract}
Shyamnangar upazila one of the potential developing upazila of Satkhira district. Addressing social aspects is very important for any sorts of development effort. The best possible use of land resources; therefore, the socio-economic aspects of Shyamnangar upazila have to be addressed to gain optimum economic benefits from agriculture, forestry, fisheries, tourism and industrial sector. The socio-economic transformation of this upazila significantly depends on the performance of the agricultural sector. Besides agriculture, fisheries, tourism, industry, weaving and livestock farming are also playing vital roles in the socio-economic development of this upazila. Although this upazila has not yet been experienced in planned industrialization but, there are some small and medium industries which are contributing largely to the socio-economic development. Over the last 10 years, the socio-economic condition of the upazila is gradually rising. The growing of small \& medium industries, business associated with agricultural products are the key element of socio-economic growth of Shyamnagar. Over the last 10 years, the socio-economic condition of the upazila is gradually rising. The growing of small \& medium industries, business associated with agricultural products are the key element of socio-economic growth of Shyamnagar.
\end{abstract}

Keywords: Sundarban; socio-economic; land zoning; environment; coastal

\section{Introduction}

Land is the most valuable resource among all natural resources of a country and holds a significant sense to human's life. Socio-economic condition, exceptional and multidimensional lifestyle, affluent cultural practice and geographical structure with various tourist attractions. Shyamnagar came into existence in 1897 as Thana and was upgraded to upazila on 1982. The upazila occupies an area of 1,968.24 sq. km. including 1485.13 sq. $\mathrm{km}$ Sundarban area and $483.11 \mathrm{sq}$. km mainland, 13 unions, and 218 villages (BBS, 2011). The conventional standard of living and resourceful, exceptional land use pattern and cultural heritage have an incredible impact on the economic, social and cultural life of the society (van der Borg and Russo, 2005). Effective use of landuse policy regulates the efficient and ethical use of land for optimal and sustainable yield not only for the government but also land owner which help to increase the national productivity (Oluwatayo et al., 2019). Considering future problems due to land degradation, land zoning addresses various social problems of the upazila. It plays a vital role for many planning and management activities concerned with the surface of the earth. Therefore, information and diversified data related to land use are needed in the analysis of environmental processes and problems that must be understood if living conditions and standards are to be improved or maintained at current levels (Anderson et al., 1976). The concept of land use and sustainable land 
management evolve since the world population began to explode (Jerin and Ishtiaque, 2014). Knowledge about land use and land cover has become increasingly important as the nation plans to overcome the problems of haphazard, uncontrolled development, deteriorating environmental quality, loss of prime agricultural lands, destruction of important wetlands, and loss of fish and wildlife habitat (Mohammad et al., 2007; Anonymous, 1976). For a small, populous country like Bangladesh, it is a foremost requirement to ensure efficient management of scares land resources. However, due to lack of effective policy planning, zoning and land use planning and regulation and lack of the enforcement of law and order, Bangladesh is embracing diversified threats and vulnerabilities to its scares land resources (Billah et al., 2018). Especially, due to rapid, uncontrolled and unplanned land use changes coastal areas of Bangladesh are facing sluggish socioeconomic development, threats of different disasters, environmental degradation and global climate changing process (DoF, 2005; Billah et al., 2018). It is claimed that about half of the coastal lands of Bangladesh face different degrees of inundation and thus limiting their effective use (Islam, 2006). It also warns that inundation situation is expected to worsen further because of the effects of climate change. This vulnerable coastal zone covers 19 out of 64 districts, where $30 \%$ of the total populations of Bangladesh live and more than half of them are poor (Parvin et al., 2009). Further, the population in the coastal areas is expected to increase from 36.8 million in 2001 to 43.9 in 2015, and to 60.8 million by 2050. Therefore, present per capita agricultural land of 0.056 ha will decrease to 0.025 ha by 2050 (Islam, 2006). Coastal area, which is one third of the territory of Bangladesh, have gone through major changes over the last half century largely due to frequent and diverse natural disasters with direct and indirect impacts on land resources and its various uses (Hossain et al., 2016; Mondal et al., 2018a; Mondal et al., 2018b). Land is being degraded and lost due to the effects of increased salinity intrusion, inundation of low-lying marshy land, floods and land erosion by the unplanned and haphazard land use of people (Ahmed, 2011; Grases et al., 2020). These unplanned and haphazard land use, along with salinity changing the traditional cultivation practices and replacing hybrid yields as well as shrimp farming in the coastal areas with a dramatically shift in the last decades (Haider and Hossain, 2013; Rahman et al., 2013; Prodhan et al., 2019). These dramatic changes in land use and shift of farming system in the coastal area have induced adverse environment impacts and hampers normal crop production throughout the year (Abedin and Shaw, 2013; Gopalakrishnan et al., 2019). Consequently, these impacts directly change the food and water supply scenario throughout the households and enhanced the hardship in their daily life (Rasel et al., 2013; Parvin et al., 2013). Following such socio economical land use conflict this study was conducted to assess the socio-economic setting and assess the updated people's perception on the implementation of land zoning; which social factors causes land degradation and reassess the socio-economic benefits of land zoning.

\section{Materials and Methods}

\subsection{Study site}

This research study has been carried out through an integrated approach with the participation of respective line departments, agencies local elected bodies and community. The detailed survey has been carried out to assess the demographic and social issue of Shyamnagar upazila, Satkhira, Bangladesh.

\subsection{Data collection technique}

\subsubsection{Primary data}

A planned questionnaire was developed containing both the closed and open ended query to collect data through face-to-face interview with the respondents. The questionnaire was formed to obtain the relevant information considering socio-demographic condition, incomes, family members, factors affecting the livelihood of the respondents and other relevant question of the fish retailers. To collect group data; participatory rural appraisal (PRA) tool such as, Focus Group Discussion (FGD) was conducted with the farmers and stakeholders. FGD sessions were held on the bazar and other most gathering places where there was spontaneous gathering were found. In some cases, we have taken help of extensive field survey and personal observation by our research team members.

\subsubsection{Secondary sources}

The secondary sources of data were district library, Satkhira; different websites and journals; Upazila Fisheries Office, Shyamnagar, and district Fisheries Office, Satkhira.

\subsection{Data processing and analysis}

After collection of data from the field, interview, FGD and personal observation; the data were verified to 
eliminate errors and inconsistencies. The qualitative data were categorized and analyzed mainly based on descriptive statistical analysis using Micro Soft excel-10.

\section{Results and Discussion}

\subsection{Resources in Shyamnagar upazila}

Most of the people of Shyamnagar upazila directly or indirectly are engaged in highly fertile multi-types agricultural land. Shrimp cultivation has also occupied a significant place in land use of this upazila. The Jamuna, Raymangal, Arpangachhia, Malancha, Hariabhanga, Chunar River are the main rivers and the Bhet canal is another notable water body of this upazila. Agriculture has occupied the huge part of the socioeconomic activities of the upazila. This upazila has 3,994 cottage industries which are leading in the industrial sector. Besides there are 1,233 husking craft mills, 1,062 tailoring shops, 681 bamboo and cane industries, 618 wooden furniture stores, 148 handicraft, 47 rice mills (auto \& semi-auto), 31 saw mills, 19 weaving/handloom factories, 13 dry fish processing factories, 8 potteries, 6 flour mills, 3 bakeries and 02 oil mills notable industries in this upazila (BBS, 2011) (Figure 1).

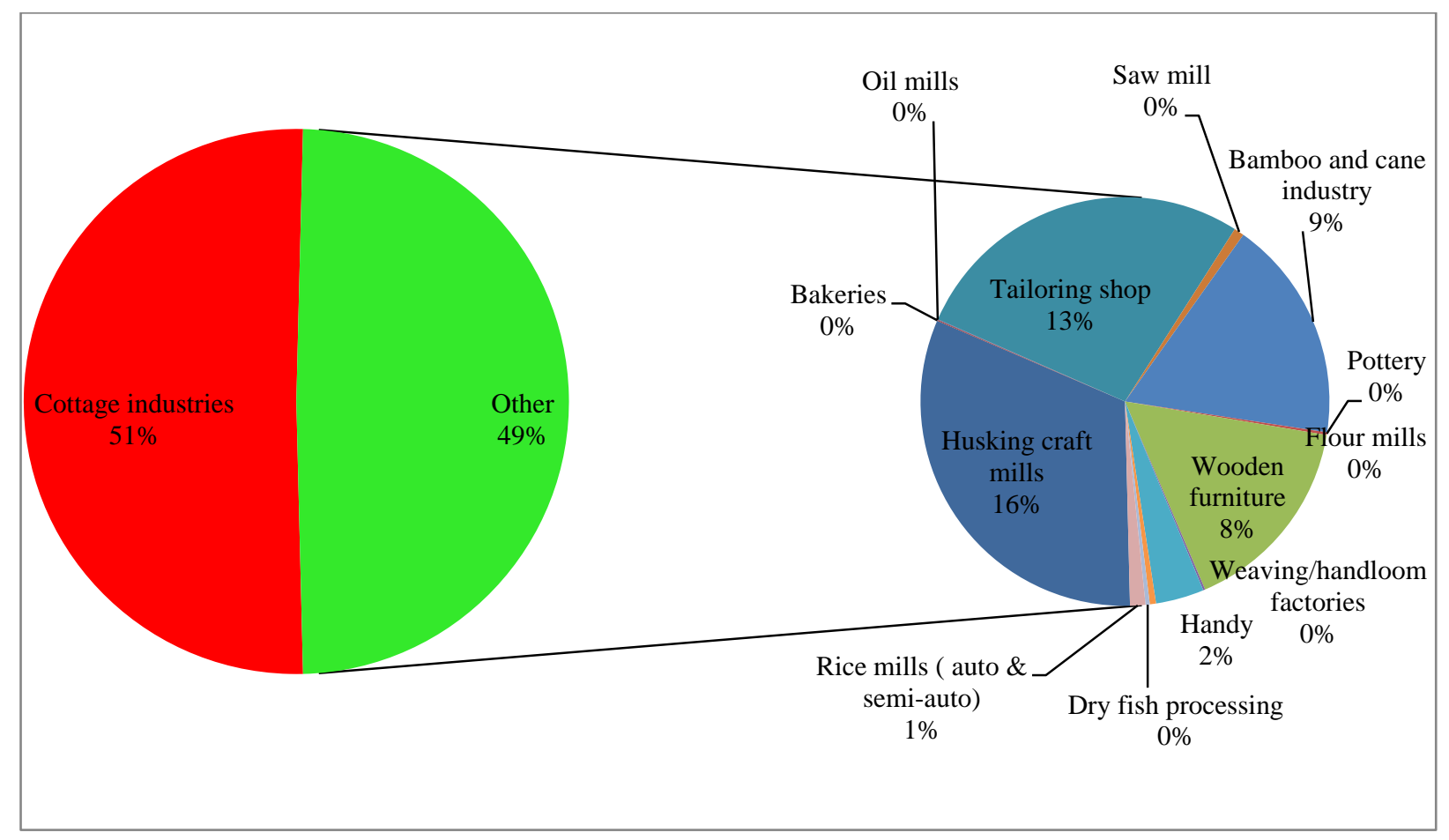

Figure 1. Industrial chart of the Shyamnagar upazila.

Urbanization is closely related to the promotion of industrialization and service sector development. Heavy industrial activities are not prevalent yet, but the expansion of proper marketing channel for agricultural products like paddy, jute, mustard, wheat, and agro-based industry could be another promising economic feature for achieving the sustainable development goal in this upazila. It is reported that in some new residential areas are established not only at the periphery of the upazila headquarter but also in other areas of this upazila. However, planned urbanization is not significant yet in the upazila. The Shyamnagar Upazila has a rich heritage in terms of education. According to the BBS (2011), the literacy rate of this upazila is $48.6 \%$ of which $53.8 \%$ are male and $43.9 \%$ are female. On the contrary, it was about $39.69 \%$ in 2001 of which $47.75 \%$ are male and $31.33 \%$ are female. There are 185 Primary Schools, 06 kindergarten Schools (pre-schooling), 41 NonGovernment Secondary Schools, 03 School \& College (operating jointly), 05 Colleges, 36 Madrasha, 12 Kawmi Madrasha, 06 Ebtedayee Madrasha, 02 Technical and Vocational Institutions. The noteworthy educational institutions are Shyamnagar Mohsin College (1972), Nurnagar Ashalata High School (1955), Bhurulia Nagbati Secondary School (1945), Patakhali Secondary School (1954), Patakhali Senior Madrasa (1945), Jainagar Hamidia Senior Madrasa (1963) (BBS, 2011). These findings are also supported by some previous study from around the Bangladesh by Islam et al. (2014) in Jashore district ; Asif et al. (2015) in Jashore district ; Hossain et al. (2015) in Dinajpur district; Islam et al. (2015) in Satkhira district ; Rahaman et al. (2015) in Jashore district; Sharif et al. (2015) in Jashore district; Islam et al. (2015) in Patuakhali district ; Sultana et al. (2015) in 
Patuakhali district; Hossain et al. (2016) Jashore district ; Vaumik et al. (2017) in Lalmonirhat district; Razeim et al. (2017) in Mymensingh district; Hossain et al. (2017) in Brahmanbaria district; Islam et al. (2017) in Meherpur district; Asif and Habib (2017) in Jashore district; Adhikary et al. (2018a) in Noakhali district; Mondal et al. (2018a) in Chittagong coastal area; Mondal et al. (2018b) in Chittagong coastal area; Adhikary et al. (2018b) in Jashore district. Although the expansion of education sector seems to be slow during last 10 years; but above mentioned educational institutions, recently established some Private Schools, NGO operated NonFormal Primary School and kindergartens are playing an important role for the promotion of education as well as the socio-economic development of Shyamnagar Upazila.

\subsection{Agriculture practices}

Agriculture is determining a sizeable part of Shyamnagar Upazila land utilization. It is observed that real land proprietor/owner are not cultivating their land and giving their land to the local small marginal farmers as rent or lease. Consequently, the land is being intensively utilized and the top surface and fertility of land are decreasing. Here paddy, mustard, jute, sugarcane, wheat, barley, betel leaf, potato, vegetables are the notable crops, but paddy is the main crop. Besides crops, fruits like mango, coconut, jujube, watermelon, jackfruit, litchi, banana, papaya, date are also grown here abundantly.

\subsection{Market places}

The marketplaces of the Shyamnagar Upazila mostly are established on the basis of agriculture and agroprocessing. The main exporting items of this upazila are paddy, jute and shrimp. The increasing number of markets also has a correlation with the life standard improvement of the people. The rural areas in this upazila have emerged in a new driver of economic growth through the development of village markets. People can sell their local products very easily and also get access of other manufacturing products from the market. The upazila has 42 several sizes markets and 6 fairs. Among them Shyamnagar Hat, Nawabeki Hat, Bhetkhali Hat, Harinagar Hat, Munshiganj Hat, Gabura Hat, Nurnagar Bazar, Baruni Mela at Ishwaripur, Katakhali Shiva Mela and Baishakhi Mela at Shyamnagar hat are notable.

\subsection{Assessment of livelihood conditions}

\subsubsection{Population and occupation}

The total population of the upazila is 330,392 in 2011 which were 327,909 in 2001. Out these 159,294 are male and 171,294 are female which were respectively 167,510 and 166,399 in 2001. The number of household is 72,279 , the average size of this household is 4.39 and population density per sq.km is 162 ; however, in 2001 these were respectively 59,885, 5.17 and 157 (Figure 2).

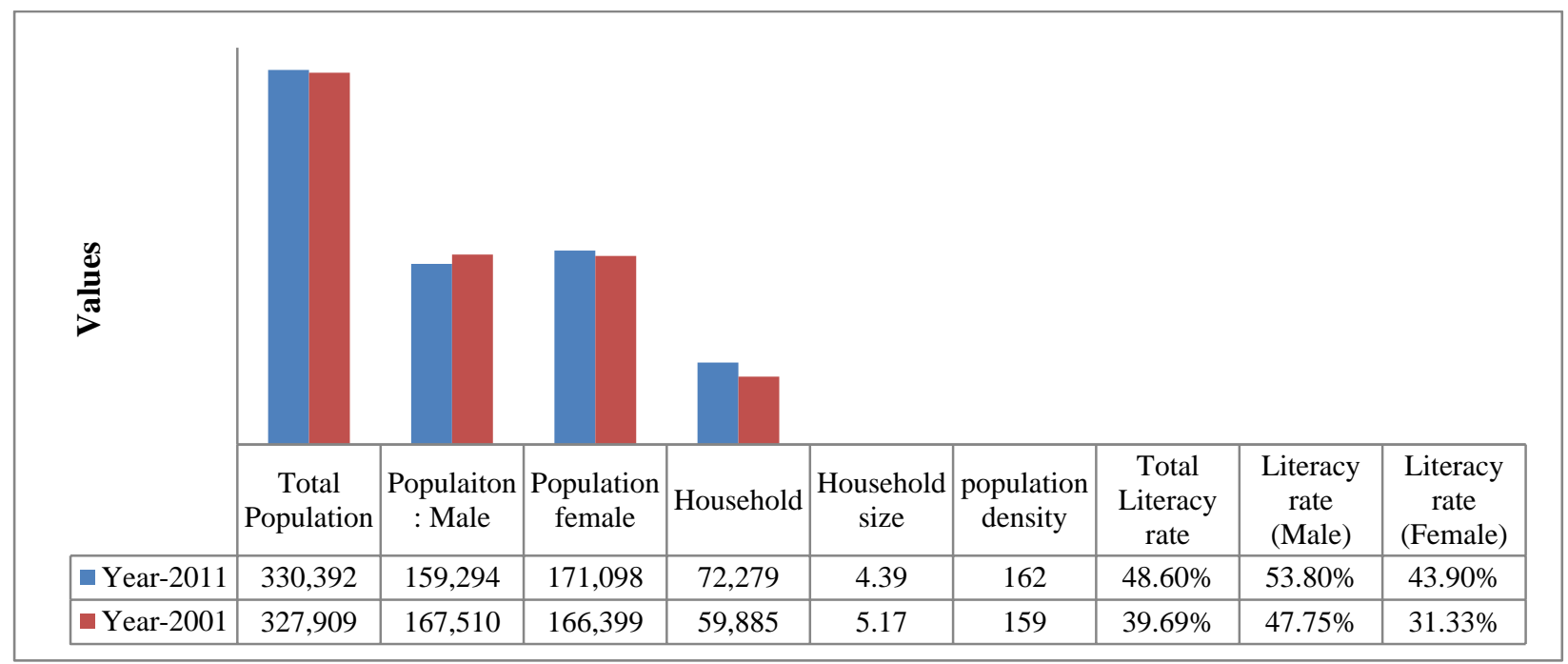

Figure 2. The comparison of demographic bar chart of Shyamnagar Upazila

People belonging to different religion and ways of life have settled in Shyamnagar for both economic and noneconomic reasons. Due to the decrease of agriculture land, river erosion threat, flood, unplanned industrialization, less scope of employment, food insecurity, climate migration, low price of agriculture products some people of Shyamnagar Upazila have already changed their inherited agriculture occupation. However, 
agriculture is the leading occupation in this upazila. The study shows, the agriculture dependent population (34.17\%) has decreased dramatically $30.81 \%$ in as 2016 compared to the 2001(64.98\%). It is explored that the percentage of non-agriculture labor increases from $6.02 \%$ to $31.67 \%$ in 2016 . This is happening mostly due to the increase of salinity in agricultural land and unplanned shrimp cultivation. Apart from these, the changes have taken place in other occupation like transport and communication $1.58 \%$ to $2.67 \%$, service $3.33 \%$ to $3.83 \%$, industries little bit higher $0.61 \%$ to $8.50 \%$, rent and remittance $0.40 \%$ to $2.66 \%$, construction $0.94 \%$ to $1.50 \%$. While the occupation like commerce decreases from $14.60 \%$ to $11.33 \%$, other $7.54 \%$ to $3.67 \%$ (BBS, 2001) (Figure 3). These findings are also supported by some previous study from around the Bangladesh by Islam et al. (2014) in Jashore district ; Asif et al. (2015) in Jashore district ; Islam et al. (2015) in Satkhira district ; Vaumik et al. (2017) in Lalmonirhat district; Islam et al. (2017) in Meherpur district; Asif and Habib (2017) in Jashore district.

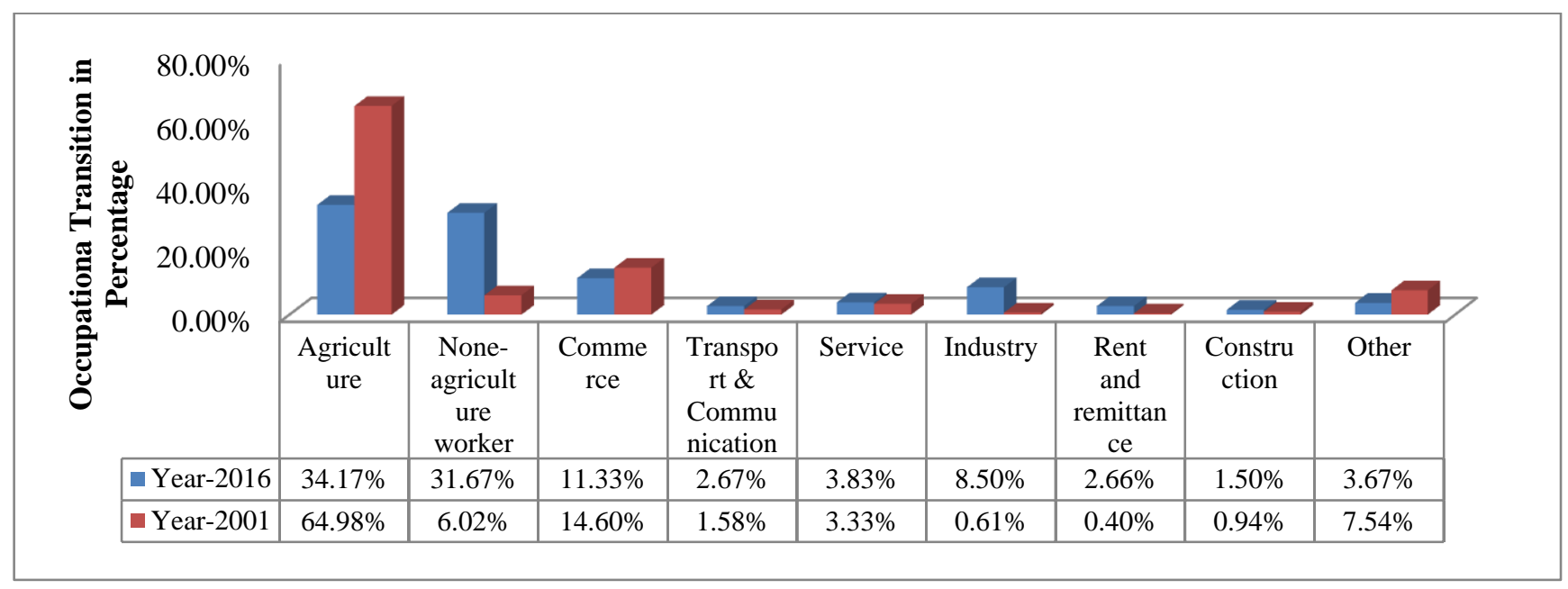

Figure 3. Comparison of occupation of Shyamnagar upazila.

\subsubsection{Socio-economic conditions of Shyamnagar}

Socio-Economic conditions depend on income status, alternative income, occupational status, educational status, family size, family type, housing condition, food consumption, nutrition, drinking water facility, sanitation facility of a particular place. The sources of drinking water are tube well 35.94\%, tap 6.46\%, pond $50.74 \%$ and others $6.86 \%$. About $44.84 \%$ of dwelling households of the upazila use sanitary latrines and $47.47 \%$ of dwelling houses use non-sanitary latrines; $7.69 \%$ of households do not have latrine facilities. Moreover, about $7.40 \%$ of the dwelling households have access to electricity. Overall housing condition of this upazila is not so good; maximum houses are made of Chun and Mud which is $26.50 \%$, Tin and Wood products 18.33\%, Tin and Bamboo 16.58\%, Building house 12.67\%, Bamboo and Chun 10.92, Semi building house 6.58, Tin house 6.5, Others 1.5 and Machang house $0.42 \%$.

Although, about 33.17 of the population of this upazila directly or indirectly lives on agriculture, but ownership of agricultural land Landowner $56.69 \%$, landless $43.31 \%$ and agricultural landowner in urban is $54.58 \%$ and rural is $56.79 \%$. Due to the river erosion, unplanned industrialization, land degradation, the numbers of landless people are increasing steadily which creates the most adverse pressure on the rural livelihood and economy. These findings are also supported by some previous study from around the Bangladesh by Adhikary et al. (2018b) in Jashore district; Mondal et al. (2018b) in Chittagong coastal area; Mondal et al. (2018a) in Chittagong coastal area; Adhikary et al. (2018a) in Noakhali district; Asif and Habib (2017) in Jashore district; Islam et al. (2017) in Meherpur district; Hossain et al. (2017) in Brahmanbaria district; Razeim et al. (2017) in Mymensingh district; Vaumik et al. (2017) in Lalmonirhat district; Hossain et al. (2016) Jashore district; Sultana et al. (2015) in Patuakhali district; Islam et al. (2015) in Patuakhali district; Sharif et al. (2015) in Jashore district; Rahaman et al. (2015) in Jashore district; Islam et al. (2015) in Satkhira district; Hossain et al. (2015) in Dinajpur district; Asif et al. (2015) in Jashore district and Islam et al. (2014) in Jashore district.

\subsection{Women participation in land use activities}

Nowadays, gender becomes the cross-cutting issue of any kind of development and overcome the socioeconomic and environmental challenge resulted by climate change. However, field study shows that women of Shyamnagar Upazila are involved in Child caring, Domestic jobs, Livestock,/Poultry rearing, Post-harvest work, 
Subsistence agriculture tasks, Peddling, Firewood collection, Domestic maid, Paddy processing, Irrigation and Water management But their participation is not up to the mark. Woman's participation could be ensured through (i) freedom of movement (ii) control over own income (iii) equal access to employment (iv) increasing literacy rates (v) ownership of Land and asset (vi) access to credit, involvement in local trade, association and market (vii) social commitment of educating daughter (viii) proactive participation in decision making (ix) domestic support for exercising rights and entitlement (x) participation in local, regional and national level committees (xi) expanding reproductive health programs and family support policies (xii) visibility and access to social space and participation in extra-familial group and social networks (Table 1).

Table 1. Social and economic activities of women and men.

\begin{tabular}{lll}
\hline Women & Men & Men \& Women \\
\hline - Child caring & $\bullet$ Farming & $\bullet$ Pottery \\
- Domestic jobs & $\bullet$ Trading & $\bullet$ Teaching \\
- Livestock/Poultry rearing & $\bullet$ Daily labor & Daily labor \\
- Post-harvest work & $\bullet$ Money gatherer from Sundarban & $\bullet$ Services \\
- Subsistence agriculture tasks & $\bullet$ Fishing/Fishing labor \\
- Peddling & $\bullet$ Working in the shrimp Ghers & $\bullet$ Small trading \\
- Firewood collection & $\bullet$ Shrimp fry collection & $\bullet$ Wood collection \\
- Domestic maid & $\bullet$ Irrigation & $\bullet$ Cultivation \\
- Paddy processing & $\bullet$ Water management & $\bullet$ Crops harvesting \\
- Irrigation and water management & $\bullet$ Construction & $\bullet$ Weaving \\
- Weaving & $\bullet$ Weaving & $\bullet$ business \\
- Working in the shrimp Ghers & $\bullet$ business & \\
- Business & & \\
- Fishing & & \\
\hline
\end{tabular}

\subsection{Land degradation, social impacts and remedial measures of Shyamnagar}

In order to make adjustment with an adverse effect of the fast growing population of Shyamnagar, the modernization of agricultural sector with proper use of land is mandatory. It is suggested that advance sciencebased agriculture with innovative use of soil and integrated farming system is required to achieve the sustainable development goal. But due to various socio-economic constraint, the massive trend of industrialization, unplanned use of land and environmental pollution; it becomes very hard job in this upazila. It is reported that the area of cultivable lands, along with the natural habitat of birds and animal species has been decreasing remarkable. Biodiversity in this upazila is also facing threats from various sources of pollution (Table 2).

Table 2. Social impact of land degradation.

\begin{tabular}{lll}
\hline $\begin{array}{l}\text { Causes of land } \\
\text { degradation }\end{array}$ & Social impacts $\quad$ Suggested measures to mitigate & Intensity and affected unions \\
\hline
\end{tabular}

- Integrated development program should be taken in cooperation with LGED, BWDB, and other line agencies.

- The formulation of Land Zoning law for the implementation of Land Zoning system and protect unplanned land use.

- Ensure people's participation in the implementation process of the development program.

- Motivational programs on Land degradation and assess its impacts on common people.
- Social life and livelihood damages.

River Erosion
- Social wealth and homestead Damages
The same causes had been revealed in 2011. Nevertheless in 2016, once again the causes have been identified. Furthermore, at present the intensity of this causes increases to a great extent in the all unions of this upazila.
- Embankment and relevant others Compare to the 2011 the structure should be constructed in intensity of river erosion has a planned way been decreased in Bhurulia,

- Victims of river erosion would be Buri Goalini, Gabura, Padma 


\begin{tabular}{|c|c|}
\hline Causes of land & Social impacts \\
\hline $\begin{array}{l}\text { Unplanned } \\
\text { shrimp cultivation }\end{array}$ & $\begin{array}{l}\text { - Social, civic utility } \\
\text { hamper. } \\
\text { - People of that society } \\
\text { migrate. } \\
\text { - Social crime Increase } \\
\text { - Deforestation, destruction } \\
\text { of mangrove ecosystems } \\
\text { and a grove species of } \\
\text { flora and fauna and } \\
\text { resulting in destruction of } \\
\text { alternative sources of } \\
\text { livelihood. } \\
\text { - Traditional rice culture } \\
\text { replaces by shrimp } \\
\text { culture. } \\
\text { - Gradual degradation in } \\
\text { the quality of land, and } \\
\text { soil-nutrient resulting in } \\
\text { accumulation of sodium } \\
\text { chloride } \\
\text { - Affecting rice production. } \\
\text { - Increase the frequency and } \\
\text { dimension of water borne } \\
\text { diseases. } \\
\text { - The number of livestock is } \\
\text { decreasing due to loss of } \\
\text { grazing land. }\end{array}$ \\
\hline
\end{tabular}

- Social life livelihood, infrastructure, public health damage.

- Social growth disrupts.

- Social economic activity hampered.

Flood/Tidal flood

- Social value deteriorates.

- Spreading of waterborne diseases.

- Enhancement of food price.

- The devastating effect on the physical and mental health
Suggested measures to mitigate

Intensity and affected unions

rehabilitated in the khas lands Pukur, Atulia, Munshiganj, with economic support Kaikhali, Nurnagar,

- Early warning about river erosion Kashimari, Ramjan, Nagar

- Initiate integrated and sustainable and Shyamnagar Union Due to development program with others the construction of some line agencies for erosion victims embankment and folder

- Ensure participation of the stakeholders in the management of shrimp farming and stricter implementation of existing laws.

- Go for zoning including declaring certain parts of the country to be non-shrimp-farm areas.

- Dis-entitlement of land less, and intensification of poverty in the area leading to prevalence of environmentally unfriendly practices

- Develop land use policy and environmental guideline for shrimp culture

- Develop optimal practices for rice-shrimp mixed culture

- Formulation of land zoning law for the implementation of land zoning system.

- Motivational programs on land degradation and its impact on people

- Construct and maintain embankments, sluice gates, rubber Compare to the 2011, dams. Bhurulia, Buri Goalini,

- Stop building infrastructure on Gabura, Padma Pukur, river flood plains. Atulia, Munshiganj, Kaikhali,

- Ensure proper drainage systems. Nurnagar,

- Move immediately to higher Kashimari, and Ramjan Nagar ground. has been identified as flood

- Stay out of the home if it is affected union. But Flood and surrounded by floodwaters and Tidal Flood has decreased in return home only when authorities Burulia, and Atulia unions. indicate it is safe.
Gradual degradation in the quality of land, and soil- Land should be used in proper Salinity nutrient accumulation of planned way through Land Zoning sodium chloride affecting rice focusing its criteria and production

- Health Hazard

- Environment pollution

Brick Field

- Affected agriculture land

- Hampered food production characteristics.

- Awareness building on negative impacts due to unplanned Brick Field

- Administrative measures to be taken

Deforestation • Shortage of forestry

Due to impact of Cyclone SIRD, Aiyla salinity had been spread out all unions of this upazila. However, Compare to 2011, the salinity is lower in, Burulia, Shaymnagar Sadar, Burigualini and kahsimari unions.

Shyamnagar Sadar, Bhurulia and Atulia has been demarcated as Brick Field affected Union

Due to the salinity increasing the deforestation is getting 


\begin{tabular}{|c|c|c|c|}
\hline $\begin{array}{l}\text { Causes of land } \\
\text { degradation }\end{array}$ & Social impacts & Suggested measures to mitigate & Intensity and affected unions \\
\hline & $\begin{array}{l}\text { - Imbalanced situation in } \\
\text { natural environment } \\
\text { - Flora and fauna are under } \\
\text { threat } \\
\end{array}$ & $\begin{array}{l}\text { - People awareness building } \\
\text { program } \\
\text { - More Plantation }\end{array}$ & $\begin{array}{l}\text { bigger in all unions of this } \\
\text { upazila compare to the } 2011 \\
\text { and before. }\end{array}$ \\
\hline $\begin{array}{l}\text { Poverty \& } \\
\text { Unemployment }\end{array}$ & $\begin{array}{l}\text { - Poorer people facing } \\
\text { financial crisis. } \\
\text { - Increase unsocial } \\
\text { activities. } \\
\text { - Deteriorate social security. } \\
\text { - Deteriorate Young } \\
\text { people's morality. }\end{array}$ & $\begin{array}{l}\text { - Providing } \\
\text { development/technical training. } \\
\text { - Creating self-employment. } \\
\text { - Creating job opportunity. } \\
\text { - Providing financial support for } \\
\text { small trades. }\end{array}$ & $\begin{array}{l}\text { Due to the vulnerable, } \\
\text { geographical structure, less } \\
\text { scope of employment poverty } \\
\text { and unemployment rate are } \\
\text { increasing rapidly. }\end{array}$ \\
\hline
\end{tabular}

\subsection{Unplanned shrimp culture and its socio-economic impact of Shyamnagar}

Shrimp culture becomes the significant component for the fisheries sector in Bangladesh. It grew from early 1970s and continuing its expansion in every year. Bangladesh has produced about 230,244MT in fiscal year 2014-2015 which was 72,809 MT in fiscal year 1986-1987. Bangladesh have exported about 44,278mt frozen shrimp (3937.6 core in Taka) in 2014-2015 which was 19,224mt (604.03 core in Taka) in fiscal year 1992-1993 (National Fish Week Compilation, July 2016) (DoF, 2005). Shrimp culture has been largely extended also in Shyamnagar upazila. But this extension has not been taken place in a coordinated and planned way. Consequently, it is creating some adverse impact on agricultural land and reduces the social security and increases the conflict among different stakeholder. This is because politically and financially strong farmers exploit marginal and small farmers. Furthermore, the marginal and small farmers have to sell their agricultural land at a very low price and even sometimes; politically strong farmers capture nearby farmer's land without any compensation. On contrary, a very insignificant numbers of people are employed in this industry.

According to field study, the exclusively agriculture dependent people are decreasing dramatically. In 2001, about $64.94 \%$ people were lived on agriculture while it decreases into $34.17 \%$. These trends are creating an undesirable pressure on rural livelihoods as well as socio-economic spectrum. Shrimps are cultivated in an unplanned ways in all unions of this upazila; however; the expansion is slower in Burigualini and Kahsimari Unions. Eventually, it creates various problem in the socio-economic area such as salinization of the soil, which decline the soil fertility; reduction in agricultural production due to limiting of agricultural land; decrease in cattle production due to the squeezing of grazing land; human health hazards, such as skin diseases and high incidence of water-borne diseases; damage of mangrove eco-systems and their biodiversity; and conflicts among the stakeholders group; agricultural labors are being unemployed; massive migration to the metropolitan city which creates pressure on slum and Family broken, early marriage, human trafficking and other social problems is created.

\subsection{Effect of unplanned land use}

The socio-economic condition of this upazila is gradually transforming agro-industry and small \& medium industry which lead to the decrease of cultivable land and green space. Here the unplanned use of land is a common scenario. Inhabitants of this upazila have no idea about Land Zoning. Large-scale urban expansion occurred in the form of unplanned development in floodplains areas. Poorly planned land use contributes to the growing flood hazard and water logging (Pandey et al., 2010). There is no control of rapidly growing unplanned brickfields and dwelling houses have been built in the agricultural land. It has an adverse impact on the socioeconomic and cultural situation, crime, unemployment, social unrest etc.

\subsection{Suggestions for sustainable land zoning}

Shyamnagar Upazila is a promising upazila for its geophysical structure and the socio-economic potentiality. The potentiality in terms of agriculture, settlements, forests, water bodies, fisheries, industrial, infrastructural developments and, tourism makes Shyamnagar upazila significant for implementation land zoning. Always creating people's awareness on land zoning and ensuring people's participation and representation in Land zoning implementation. Advocacy and Social mobilization through advertisement in print and electronic media on land zoning and conducting public hearing about land zoning. Involving local government and local administration in the Land Zoning activities. Classification of land according to its excellence and 
characteristics for its optimum use and formation of a Land Zoning implementation and monitoring committee at rural level (Yusoff et al., 2014; Yusoff et al., 2016).

\section{Conclusions}

This study will help us to understand the socio-economic setting and finally discover the potential socioeconomic benefits of land zoning. Proper implementation of Land Zoning will open a new window for development of advanced transport and communication, development of small medium industry, tourism, digitalization of government service, reduction of land related conflicts, preservation of culture and heritage and so on. Additionally land-based social conflicts can also be reduced through developing a practical land zoning.

\section{Conflict of interest}

None to declare.

\section{References}

Abedin MA and R Shaw, 2013. Agriculture adaptation in coastal zone of Bangladesh. In: Climate change adaptation actions in Bangladesh. Disaster risk reduction (methods, approaches and practices), Eds., Shaw R., Mallick F. and A. Islam, Springer, Tokyo, pp. 207-225.

Adhikary RK, S Kar, A Faruk, A Hossain, MNM Bhuiyan and AA Asif, 2018a. Contribution of aquaculture on livelihood development of fish farmer at Noakhali, Bangladesh. Asian-Australas. J. Biosci. Biotechnol., 3: 106-121.

Adhikary MR, MA Rahman, AA Asif and RK Adhikary, 2018b. Socio-economic status of fish retailers in Jashore sadar, Bangladesh. Asian Australas. J. Food Saf. Secur., 2: 100-108.

Ahmed A, 2011. Some of the major environmental problems relating to land use changes in the coastal areas of Bangladesh: A review. J. Geogra. Reg. Plan., 4:1-8.

Anderson JR, EE Hardy, JT Roach and RE Witmer,1976. A land use land cover classification system for use with remote sensing data: a revision of the land use classification system. In Professional Paper. https://doi.org/10.3133/PP964

Anonymous, 1976. Land use classification system adopted. Eos, Trans. American Geophy. Uni., 57: 726.

Asif AA and MAB Habib, 2017. Socio-economic condition of fish farmers of Jhikargachha upazila in Jessore district, Bangladesh. Asian J. Med. Biol. Res., 3: 462-475.

Asif AA, MA Samad, MH Rahman, MA Farid, SM Yeasmin and BMS Rahman, 2015. Socio-economic condition of fish fry and fingerling traders in greater Jessore region, Bangladesh. Int. J. Fish. Aqua. Stud., 2: 290-293.

Bangladesh Bureau of Statistics (BBS), 2011. District statistics 2011, Satkhira. Dhaka: Bangladesh Bureau of Statistics, Statistics and Informatics Division, Ministry of Planning, The Government of People's Republic of Bangladesh.

Billah MM, D Bartlett, R Simon, MR Khan, AAM Siddiqui, SS Mahmud and MAI Mondal, 2018. Integrated Coastal Zone Management in the UK and Bangladesh. Int. J. Bus. Soc. Sci. Res., 7: 119-126

DoF, 2005. Fishery Statistical Yearbook of Bangladesh 2003-2004. Fisheries Resources Survey System, Department of Fisheries, Ministry of Fisheries and Livestock, Matshya Bhaban, Dhaka, Bangladesh.

Gopalakrishnan T, M Hasan, A Haque, S Jayasinghe and L Kumar, 2019. Sustainability of coastal agriculture under climate change. Sustainability, 11: 7200.

Grases A, V Gracia, M García-León, J Lin-Ye and JP Sierra, 2020. Coastal flooding and erosion under a changing climate: implications at a low-lying coast (Ebro Delta). Water, 12: 346.

Haider MZ and MZ Hossain, 2013. Impact of salinity on livelihood strategies of farmers. J. Soil Sci. Plant Nutri., 13: 417-431.

Hossain A, MAR Hossain, AA Asif, S Ahmed and A Satter, 2017. Fish fermentation in Lalpur, Brahmanbaria district: ecological implication and value chain analysis. Asian-Australas. J. Biosci. Biotechnol., 2: 159-172.

Hossain MA, AA Asif, MA Zafar, MT Hossain, MS Alam and MA Islam, 2015. Marketing of fish and fishery products in Dinajpur and livelihoods of the fish retailers. Int. J. Fish. Aqua. Stud., 3: 86-92.

Hossain MZ, A Pal, MA Hasan, MS Parvej, N Nahar and AA Asif, 2016. Nutritional status and sociodemographic characteristics of the people of south-west coastal region in Bangladesh. Asian-Australas. J. Biosci. Biotechnol., 1: 323-332.

Hossain MZ, A Pal, MA Hasan, MS Parvej, N Nahar and AA Asif, 2016. Nutritional status and sociodemographic characteristics of the people of south-west coastal region in Bangladesh. Asian-Australas. J. Biosci. Biotechnol., 1: 323-332. 
Islam FMK, AA Asif, M Ahmed, MS Islam, B Sarker, MA Zafar and M Rahman, 2017. Performances of resource poor households in aquaculture practices in sadar upazila, Meherpur, Bangladesh. Int. J. Fish. Aqua. Stud., 5: 281-288.

Islam MA, AA Asif, MA Samad, BMS Rahman, MH Rahman, A Nima and SM Yeasmin, 2014. Socioeconomic conditions of the fish farmers in Jessore, Bangladesh. Int. J. Bus. Soc. Sci. Res., 2: 153-160.

Islam MM, AA Asif, S Vaumik, MA Zafar, BMN Sharif, MH Rahman and S Shahriyar, 2015. Socio economic status of fry collectors at Sundarban region. Int. J. Fish. Aqua. Stud., 3: 89-94.

Islam MR, 2006. Managing diverse land uses in coastal Bangladesh: institutional approaches. In: Environment and livelihoods in tropical coastal zones: managing agriculture-fishery-aquaculture conflicts, Eds., Hoanh C.T., T.P. Tuong, J.W. Gowing and B. Hardy, MI: CABI Publication, pp. 237-248.

Islam MR, MJH Biswas, MGR Akanda, MR Amin, IM Hasan, AA Asif, S Sheheli and BMN Sharif, 2015. Attitude of the farmers towards climate change effect on agriculture. Asian J. Med. Biol. Res., 1: 367-379.

Jerin T and A Ishtiaque, 2014. Detailing rural land use of Coastal Bangladesh: A micro-level study. Malaysian J. Soc. Space, 10:1-17.

Mohammad NA, SAS Mastura and JM Akhir, 2007. Land use evaluation for Malaysia's Kuala Selangor using remote sensing and GIS technologies. Malaysian J. Soc. Space, 3:1 - 19.

Mondal MAI, MA Kader, AH Choudhury, MG Mustafa, MRU Nabi, MM Billah, AA Asif and AAM Siddiqui, 2018a. Socio-economic uplifting analysis of ESBN fishery of the coastal villages, Kumira and Kattoli, Chittagong, Bangladesh. Int. J. Res. Grant., 6: 248-263.

Mondal MAI, MA Kader, MRU Nabi, AAM Siddiqui, MM Billah and AA Asif, 2018b. Bio-economic analysis of ESBN fishery of Kumira, the coastal area of Chittagong, Bangladesh. Asian J. Med. Biol. Res., 4: 315322.

Oluwatayo IB, O Timothy and AO Ojo, 2019. Land acquisition and use in Nigeria: Implications for sustainable food and livelihood security, land use - assessing the past, envisioning the future, Luís Carlos Loures, IntechOpen, DOI: 10.5772/intechopen.79997.

Pandey AC, SK Singh and MS Nathawat, 2010. Waterlogging and flood hazards vulnerability and risk assessment in Indo Gangetic plain. Nat. Haza., 55: 273-289.

Parvin GA, F Takahashi and R Shaw, 2008. Coastal hazards and community-coping methods in Bangladesh. J Coast Conserv., 12:181-193.

Prodhan S, BB Sikder and M Nasreen, 2019. Impacts and challenges associated with shrimp cultivation in Parulia union, Satkhira, Bangladesh: An empirical study. J. Asiatic Soc. Bangladesh Sci., 45: 55-69.

Rahaman MM, MA Zafar, BMN Sharif, P Paul, AA Asif, MM Islam and MI Hossain, 2015. Tilapia (Oreochromis mossambicus) marketing system in greater Jessore region, Bangladesh. Int. J. Fish. Aqua. Stud., 3: 95-103.

Rahman MM, VR Giedraitis, LS Lieberman, MT Akhtar and V Taminskienė, 2013. Shrimp cultivation with water salinity in Bangladesh: The implications of an ecological model. Universal J. Pub. Heal., 1: 131-142.

Rasel HM, MR Hasan, B Ahmed and MSU Miah, 2013. Investigation of soil and water salinity, its effect on crop production and adaptation strategy. Int. J. Water Res. Env. Eng., 5: 475-481.

Razeim MA, MG Farouque, MA Sarker, AA Asif and M Ahmed, 2017. Attitude of farmers towards Pangas farming for their livelihood improvement. Asian-Australas. J. Biosci. Biotechnol., 2: 106-119.

Sharif BMN, AA Asif, S Vaumik, MA Zafar, MM Islam and MA Samad, 2015. Socio-economic condition of fish farmer and trader at the village of Pitamborpur in Chaugachha upazilla in Jessore, Bangladesh. Int. J. Fish. Aqua. Stud., 3: 212-217.

Sultana N, AA Asif, MMI Dihider, SM Ahsan and FS Maraj, 2015. Usefulness of farm women training programmes in livelihood security. Int. J. Bus. Soc. Sci. Res., 4: 13-24.

van der Borg J and AP Russo, 2005. The impacts of culture on the economic development of cities. Report submitted to European Institute for Comparative Urban Research, Erasmus University Rotterdam. pp. 1-404.

Vaumik S, SK Sarker, MS Uddin, MT Alam, A Satter, AA Asif, 2017. Constraints and prospects of fish farming in Lalmonirhat District. Int. J. Bus. Soc. Sci. Res., 5: 201-210.

Yusoff SM, F Yusof and AF Arshad, 2014. An analysis of local plan for development control at local planning level in the state of Selangor. Proc. Soc. Behav. Sci., 153: 574-584.

Yusoff SM, F Yusof and AF Arshad, 2016. Effectiveness form and content of the local plan as a tool for the quality of life in urban area. Proc. Soc. Behav. Sci., 222: 897-906. 